\title{
Validating an Amharic Version of the 36-item Short Form Health Survey (SF-36) in Individuals With Leprosy in Ethiopia.
}

\author{
Saba Maria Lambert ( $\nabla$ sabalambert@hotmail.com ) \\ London School of Hygiene \& Tropical Medicine https://orcid.org/0000-0003-4376-5495 \\ Shimelis D. Nigusse \\ ALERT centre \\ Digafe T. Alembo \\ ALERT center \\ Stephen L. Walker \\ London School of Hygiene \& Tropical Medicine \\ Peter G. Nicholls \\ University of Southampton Faculty of Health Sciences \\ Diana N.J. Lockwood \\ London School of Hygiene \& Tropical Medicine
}

\section{Research}

Keywords: leprosy, quality of life, HRQOL, Amharic, SF-36, WHOQOL-BREF, Ethiopia

Posted Date: August 17th, 2021

DOI: https://doi.org/10.21203/rs.3.rs-801232/v1

License: (c) (i) This work is licensed under a Creative Commons Attribution 4.0 International License. Read Full License 


\section{Abstract}

Background: Health-related quality of life (HRQoL) has now become an indispensable outcome measure in many randomized clinical trials and other studies. It provides the patient's voice in measuring health improvement or decline and assessing treatment effectiveness. A validated Amharic version of HRQoL assessment tool was needed for leprosy clinical trials in Ethiopia. The SF-36 was chosen but a validated Amharic version was not available. We describe how this was developed.

Methods: The SF-36 was translated from English into Amharic and evaluated for content acceptability in a patient focus group. Back translation was performed. Validity and reliability of Amharic SF-36 in leprosy affected individuals was tested with 100 patients with leprosy attending the leprosy clinic at ALERT hospital and compared to the Amharic version of the WHOQOL-BREF.

Results: Amharic translations of both the WHOQOL-BREF and the SF-36 had good reliability and validity amongst leprosy affected individuals. Internal consistency reliability estimates for each domain/scale exceeded 0.70 . The Amharic SF-36 had better convergent and discriminant validity than WHOQOL-BREF in this group of patients. Good known-group validity was seen in both WHOQOL-BREF and SF-36 in leprosy affected patients. Amharic SF-36 had good inter-rater reliability with seven out of 8 domains scoring above 0.8 in intra-class correlation.

Conclusion: This Amharic version of the SF-36 is a valid instrument to measure HRQoL in clinical trials involving leprosy affected individuals in Ethiopia.

\section{Background}

Health-related quality of life (HRQoL) as a patient-centred outcome measure is increasingly being included in clinical trials but is rarely used in comparative clinical trials in leprosy.

Leprosy is a chronic granulomatous infection principally affecting the skin and peripheral nerves caused by the obligate intracellular organism Mycobacterium Leprae (1). In 2020, the WHO reported 202185 new cases globally (2). Multi-drug therapy (MDT) cures the infection, but the damage done to nerves by $M$. leprae and immunological reactions leads to disability and visible deformity mainly affecting eyes, hands and feet. Patients with leprosy are often stigmatised and experience economic hardship (3), both because of stigma (4) and poor health. The treatment of leprosy reactions is currently inadequate, with prednisolone being the main drug used with limited success and high rates of adverse effects (5). Identifying better agents for treating leprosy reactions and understanding the effects of these treatments on HRQoL is a priority (6).

Due to the international nature of clinical research, the need for cross-culturally valid patient reported outcomes questionnaires has grown considerably. For cross-cultural clinical research, the ultimate goal is to pool data across languages in order to evaluate the effect of treatment on an outcome measured by the same questionnaire. To achieve this objective, for each language, the concepts assessed by each item should be as identical as possible, the aggregation of items should result in the same constructs and the metric scales should be similar.

When a questionnaire has already been developed and used in one culture, the sequential approach based on a thorough translation is essential for controlling potential bias at the level of the item. Many translation guidelines have been published and most describe a forward-backward translation by a qualified team, followed by pilot testing with patients. This does rely on the assumption that the constructs of a questionnaire, and their content, are relevant and equivalent across cultures.

At the start of this study, a few cross-sectional studies of HRQoL in leprosy patients had been published. The three main tools used were the World Health Organisation Quality of Life Bref (WHOQOL-BREF) (7-10), the Dermatology Life Quality Index (DLQI) (11, 12) and the Short Form-36 Health Survey SF-36 $(13,14)$.

The WHOQOL-BREF is a shortened version of the original WHOQOL-100, with the following domains: physical health, psychological health, level of independence, social relationships, spiritual and environmental conditions (15). The validated Amharic WHOQOL-BREF had been used in an assessment of 749 women displaced by conflict (16), and of 346 individuals affected by podoconiosis (17).

The DLQI consists of ten questions, designed to assess the effect of dermatological conditions on HRQ in adults. It covers several dimensions of life quality, including pain, embarrassment, interference with activities, and social and sexual relationships with questions aimed at how the patient/individual has felt in the last week. An Amharic version of the DLQI was used to study podoconiosis in Ethiopia (18). The questions in the DLQI do not capture information on the impact of nerve damage and disability caused by leprosy.

The SF-36 was developed as a way of measuring the outcome of healthcare delivery in the United States (19). The SF-36 comprises 36 items assessing eight health concepts using multi-item scales and is administered using a past four weeks reporting interval. It tests physical functioning (10 items), role limitations caused by physical health problems (4 items), role limitations caused by emotional problems (3 items), social functioning (2 items), emotional well-being (5 items), energy/fatigue (4 items), pain (2 items), general health perception (5 items) and 
perceived change in health during the last 12 months. Two summary scores can be calculated: a mental health component summary score (MCS) and a physical health component summary score (PCS).

Four studies reported using the SF-36 in Ethiopia. A study published in the Ethiopian Medical Journal (20) evaluated the SF-36 to obtain normative data in a general health survey in order to establish general population norms and to describe the effects of socio-demographic factors on SF 36. It concluded that the Amharic SF-36 had acceptable psychometric properties and construct validity. The translation system used was not reported. It was later used to assess HRQoL in 271 individuals with schizophrenia (21), and 315 individuals with bipolar disease (22) and 420 people living with HIV and on anti-retroviral therapy (23).

Unfortunately, despite many attempts, we were not able to obtain a copy of this Amharic version of the SF-36, and the developers of SF-36 did not hold an Amharic version.

Although cross validation of item selection and scoring of SF-36 has been done (24), this has often been done on patients living in developed countries with similar standards of living. At first glance, the face validity of some SF-36 items appear questionable for patients in low-income settings, such as questions about "playing golf", "bowling", "pushing a vacuum cleaner" and "climbing several flights of stairs" in a country where only urban buildings have several floors. This observation pointed to a need to explore the construct validity of the SF-36 before adopting it for use with leprosy patients in our study in Ethiopia.

Validation of a translated questionnaire can be done by comparing its reliability and validity with a validated QOL tool in that language. Previous comparisons between SF-36 and WHOQOL-BREF have been successfully done in patients with HIV, showing that there are good correlations between the corresponding domains/scales of the two instruments (25). Validation of the Amharic SF-36 in our study was done by comparison with an already validated Amharic WHOQOL-BREF $(16,26)$. Another measure of validity for SF-36 in leprosy patients was to assess known-group validity by comparing SF-36 scores with symptom frequency and symptom severity in leprosy patients. The decision to select SF36 for our clinical trial if it proved superior to WHOQOL BREF was taken.

\section{Methodology}

Study setting

The study took place at ALERT hospital, a tertiary referral centre for leprosy, in Addis Ababa, Ethiopia.

Study aim: To validate an Amharic version of SF36.

We hypothesized that if both instruments captured the health related QOL of leprosy patients, then:

1. The corresponding domain/scale of both instruments should be positively correlated, i.e. the physical, psychological, and social domains of the WHOQOL-BREF should be significantly correlated with PF, MH and SF scales of the SF-36 respectively;

2. The physical and psychological domains of the WHOQOL-BREF should have weak associations with MCS and PCS of the SF-36, respectively;

3. The domain/scale score of both instruments should be positively correlated with self-perceived health status (question 2 in both instruments);

4. The domain/scale score of both instruments should be inversely correlated with the number and intensity of leprosy related symptoms.

Sample size

After review of published literature, a minimum sample size of 30 participants was the usual size in validation studies. We decided on 50 participants for the comparison of SF-36 to WHOQOL -BREF and 50 participants to assess inter-rater reliability, giving a total of 100 participants for the relationship between SF-36 scores and leprosy symptoms.

\section{Ethical approval}

Ethical approval was obtained as part of the larger clinical trial from Ethics Committee of the London School of Hygiene and Tropical Medicine (5376), the ALERT and AHRI Ethical Review Committee (AA/ht/248/09), the National Ethics Review Committee of Ethiopia (RDHE/34-90/2009). Written informed consent was obtained in Amharic. Data was anonymised and stored in a password protected Access database.

\section{Instrument translation and adaptation}

The SF-36 questionnaire was translated by two native Amharic speakers fluent in English. The translators, two doctors, a social worker and a nurse reviewed the translation to ensure the translation replicated the original as closely as possible but was appropriate for the socio-economic and cultural setting. For example, "pushing a vacuum cleaner, bowling, or playing golf" were removed, leaving only "moving a table" as an example for moderate activity. The two previous reports on the use of Amharic SF-36 mentioned that "climbing stairs" was replaced by "walking 
up a hill" in their translation, but we felt comfortable using "climbing stairs" in an urban setting, with "walking up a hill" as a second option. Distance in miles and yards were changed to kilometres and metres which are more commonly used in Ethiopia. Following this, our Amharic version was then discussed in a focus group of two doctors, two nurses, an occupational therapist and seven patients. The patients were of various ages and leprosy experience - two were newly diagnosed patients, three patients had leprosy reactions and two long-term patients had attended for management of neuropathic ulcers. After minor changes in wording, a final version was agreed and back translated into English by an independent translator. The new English translation was then compared with the original SF-36 for conceptual equivalence and found to be satisfactory by two English language native speakers. The final Amharic SF-36 version (Appendix 2) was the tested for validity and reliability.

Validity and reliability of Amharic SF-36 in leprosy patients

Amharic speaking patients with leprosy were interviewed after obtaining informed consent, by a nurse or social worker trained in questionnaire administration.

Demographic and clinical data were collected using a standard form (Appendix 1). Disability grading was assessed using the Eye Hand Foot (EHF) score recommended by the WHO which has a range of 0-12. The higher the score the greater the disability (27).

Participants were alternatively allocated to one of the two groups. Group A were interviewed by the same interviewer, on the same day with two different questionnaires: Amharic WHOQOL-BREF and Amharic SF-36. Individuals in Group B were interviewed separately by two interviewers, on the same day with the Amharic SF-36. Each interviewer was blinded to the other's interview results.

\section{Statistical analysis}

Reverse score items were adjusted in SF-36 for questions SF02, GH02, GH04, VT03, VT04, MH01, MH02, MH04 and in WHOQOL-BREF for questions 3, 4 and 26. The scoring systems recommended by the tool developers were followed for both the WHOQOL-BREF (15) and the SF-36 (19). Data were then analysed in the following aspects:

1. Descriptive statistics

2. Tests of scaling assumptions (multi-trait scaling methods)

3. Reliability (Cronbach's a for internal consistency reliability)

4. Convergent and discriminant validity (correlations between scores of the two instruments)

5. Known-groups validity (correlations between scores and symptoms)

6. Inter-rater reliability (correlation between two interviewers per domain/ scale and global score).

Data were analysed using Statistical Package for the Social Sciences (SPSS) for Windows, version 20. Quality Metric Health Outcomes Scoring Software 4.0 was used to derive SF-36 scores.

\section{Results}

\section{Baseline Characteristics}

The characteristics of the 100 participants are summarized in Table 1 
Characteristics of 100 patients with leprosy enrolled in this study

\begin{tabular}{|c|c|c|c|c|}
\hline \multicolumn{2}{|l|}{ Characteristics of patient group } & $\begin{array}{l}\text { Total group } \\
\mathrm{n}=100(\%)\end{array}$ & $\begin{array}{l}\text { Group A: WHOQOL-BREF } \\
\text { vs.SF-36 comparison group }\end{array}$ & $\begin{array}{l}\text { Group B: } \\
\text { SF-36 inter-rater } \\
\text { reliability group }\end{array}$ \\
\hline Number of patients & & 100 & 50 & 50 \\
\hline Age (years) Median & & 35 & 33.5 & 37.4 \\
\hline Female: male ratio & & $1: 3$ & $2: 3$ & $1: 2$ \\
\hline \multirow[t]{4}{*}{ Education level } & None & $42 \%$ & $17(34 \%)$ & $25(50 \%$ \\
\hline & Primary & $30 \%$ & $17(34 \%)$ & $13(26 \%)$ \\
\hline & Secondary & $26 \%$ & $15(30 \%)$ & $11(22 \%)$ \\
\hline & Tertiary & $2 \%$ & $1(2 \%)$ & $1(2 \%$ \\
\hline \multirow[t]{2}{*}{ Literacy } & No & $42 \%$ & $18(36 \%)$ & $24(48 \%)$ \\
\hline & Yes & $58 \%$ & $32(64 \%)$ & $26(52 \%)$ \\
\hline \multirow[t]{2}{*}{ Lives: } & Alone & $16 \%$ & $5(10 \%)$ & $11(22 \%)$ \\
\hline & With others & $84 \%$ & $45(90 \%)$ & $39(78 \%)$ \\
\hline \multirow[t]{2}{*}{ Residence: Rural/Urban } & Rural & $27 \%$ & $10(20 \%)$ & $17(34 \%)$ \\
\hline & Urban & $73 \%$ & $40(80 \%)$ & $33(66 \%)$ \\
\hline $\begin{array}{l}\text { Duration of leprosy symptoms } \\
\text { (years: mean range) }\end{array}$ & & $2.9(0-14)$ & $2.8(0-14)$ & $3(0-10)$ \\
\hline On MDT & & $41 \%$ & $22(44 \%)$ & $19(38 \%)$ \\
\hline On Steroids for reactions & & $81 \%$ & $42(94 \%)$ & $39(78 \%)$ \\
\hline \multirow[t]{2}{*}{ Type of leprosy reaction } & ENL & $20 \%$ & $9(18 \%)$ & $11(22 \%)$ \\
\hline & T1R & $61 \%$ & $33(66 \%)$ & $28(56 \%)$ \\
\hline \multirow[t]{2}{*}{ Health status at today's attendance } & Sick & $31 \%$ & $19(38 \%)$ & $12(24 \%)$ \\
\hline & Stable & $69 \%$ & $31(62 \%)$ & $38(76 \%)$ \\
\hline \multirow[t]{3}{*}{ Hospital admission } & Never & $66 \%$ & $33(66 \%)$ & $33(66 \%)$ \\
\hline & Past & $27 \%$ & $14(28 \%)$ & $13(26 \%)$ \\
\hline & Presently & $7 \%$ & $3(6 \%)$ & $4(8 \%)$ \\
\hline \multirow[t]{3}{*}{ Disability grading (Total EHF score) } & None $=0$ & $24 \%$ & $15(30 \%)$ & $9(18 \%)$ \\
\hline & Moderate = 1-4 & $55 \%$ & $18(36 \%)$ & $37(74 \%)$ \\
\hline & Severe $=5-12$ & $21 \%$ & $17(34 \%)$ & $4(8 \%)$ \\
\hline \multirow[t]{3}{*}{ Number of positive symptoms: } & None & $5 \%$ & $5(10 \%)$ & $0(0 \%)$ \\
\hline & 1-3 symptoms & $16 \%$ & $9(18 \%)$ & $7(14 \%)$ \\
\hline & 4-7 symptoms & $79 \%$ & $36(72 \%)$ & $43(86 \%)$ \\
\hline \multirow{3}{*}{$\begin{array}{l}\text { Severity of symptoms (higher or lower than group } \\
\text { mean of reported severity of symptoms) }\end{array}$} & None & $4 \%$ & $4(8 \%)$ & 0 \\
\hline & Moderate (lower & $50 \%$ & $23(46 \%)$ & $27(54 \%)$ \\
\hline & $\begin{array}{l}\text { than group mean) } \\
\text { Severe (higher } \\
\text { than group mean) }\end{array}$ & $46 \%$ & $23(46 \%)$ & $23(46 \%)$ \\
\hline
\end{tabular}




\begin{tabular}{|lllll|}
\hline Characteristics of patient group & & $\begin{array}{l}\text { Total group } \\
n=100(\%)\end{array}$ & $\begin{array}{l}\text { Group A: WHOQOL-BREF } \\
\text { vs.SF-36 comparison group }\end{array}$ & $\begin{array}{l}\text { Group B: } \\
\text { SF-36 inter-rater } \\
\text { reliability group }\end{array}$ \\
\hline Self-perceived health status (GH1 from SF-36): & Poor & $7 \%$, & $3(6 \%)$, & $4(8 \%)$, \\
& Fair & $40 \%$, & $20(40 \%)$, & $20(40 \%)$ \\
& Good & $33 \%$, & $15(30 \%)$, & $(36 \%)$ \\
& Very Good & $16 \%$ & $8(16 \%)$ & $8(16 \%)$ \\
& Excellent & $4 \%$ & $4(8 \%)$ & 0 \\
\hline
\end{tabular}

There was a 1:3 ratio of female to males in the group of 100 participants interviewed. Although only $2 \%$ had received tertiary education, $58 \%$ had been to school and were literate. $27 \%$ of participants interviewed were rural residents. Most participants (81\%) attending the clinic were being treated for a reaction and were on steroids; only $31 \%$ were acutely unwell on the day of the interview. A total of $41 \%$ were on MDT.

The EHF scores were categorized into "0= No disability" (24\%), "1-4= Moderate disability" (55\%) and "5-12= Severe disability" (21\%). A high percentage (79\%) of participants reported experiencing more than four leprosy related symptoms.

All the participants were interviewed; none self-completed the questionnaires.

\section{Descriptive statistics for the WHOQOL-BREF vs SF-36 comparison}

Each of the 50 Group A participants interviewed had their scores analysed by domains for both questionnaires. The score distribution is shown in table 2 .

The physical and environmental domains of WHOQOL-BREF and six out of the 8 scales of the SF-36 were positively skewed, indicating distributions with more participants scoring lower than the mean group score.

All four domains of the WHOQOL-BREF had trivial floor and ceiling effects. Ceiling effect is measured by the proportion of people getting the highest possible score, whilst floor effects reflect the proportion of people receiving the lowest possible score. The highest ceiling effect was noted in the physical functioning (PF) scale of SF-36 (34\%) indicating that one third of participants were able to perform physical activities without limitations. Noteworthy ceiling effects were observed for the role-disability scales ( $24 \%$ for role physical (RP) and $22 \%$ for role emotional $(\mathrm{RE}))$ in the SF-36, indicating that almost one quarter of individuals affected by leprosy did not feel that their physical health or emotional problems resulted in difficulties with work or other activities. A modest ceiling effect was observed for social functioning (SF) with $20 \%$ of participants able to perform social activities without interference. 
Table 2

Score distribution of the WHOQOL-BREF and SF-36 $(n=50)$

\begin{tabular}{|c|c|c|c|c|c|c|c|c|c|c|}
\hline & $\begin{array}{l}\text { Number of } \\
\text { items }\end{array}$ & Mean & $\begin{array}{l}\text { Standard } \\
\text { Deviation }\end{array}$ & Minimum & $\begin{array}{l}\text { Percentile } \\
25\end{array}$ & Median & $\begin{array}{l}\text { Percentile } \\
75\end{array}$ & Maximum & $\begin{array}{l}\text { Percent } \\
\text { scoring at } \\
\text { the floor }\end{array}$ & $\begin{array}{l}\text { Percent } \\
\text { scoring at } \\
\text { the ceiling }\end{array}$ \\
\hline \multicolumn{11}{|c|}{$\begin{array}{l}\text { WHOQOL- } \\
\text { BREF }\end{array}$} \\
\hline PHYS & 7 & 51.2 & 16.0 & 10.7 & 39.3 & 50.0 & 64.3 & 75.0 & $2.00 \%$ & $8.00 \%$ \\
\hline PSYCH & 6 & 53.7 & 16.4 & 12.5 & 41.7 & 58.3 & 66.7 & 80.0 & $2.00 \%$ & $2.00 \%$ \\
\hline SOCIAL & 3 & 46.1 & 22.6 & 0.0 & 33.3 & 50.0 & 66.7 & 75.0 & $8.00 \%$ & $16.00 \%$ \\
\hline ENVIR & 8 & 40.9 & 14.9 & 12.5 & 31.3 & 40.6 & 50.0 & 71.9 & $2.00 \%$ & $2.00 \%$ \\
\hline \multicolumn{11}{|l|}{ SF-36 } \\
\hline PF & 10 & 71.5 & 33.9 & 0.0 & 50.0 & 90.0 & 100.0 & 100.0 & $6.00 \%$ & $34.00 \%$ \\
\hline $\mathrm{RP}$ & 4 & 61.5 & 29.1 & 0.0 & 43.8 & 50.0 & 93.8 & 100.0 & $4.00 \%$ & $24.00 \%$ \\
\hline $\mathrm{BP}$ & 2 & 50.9 & 30.3 & 0.0 & 32.0 & 42.0 & 74.0 & 100.0 & $8.00 \%$ & $18.00 \%$ \\
\hline $\mathrm{GH}$ & 5 & 50.0 & 24.8 & 5.0 & 27.0 & 45.0 & 67.0 & 100.0 & $2.00 \%$ & $4.00 \%$ \\
\hline VT & 4 & 55.0 & 22.5 & 12.5 & 50.0 & 50.0 & 75.0 & 100.0 & $2.00 \%$ & $6.00 \%$ \\
\hline SF & 2 & 48.0 & 33.9 & 0.0 & 25.0 & 50.0 & 62.5 & 100.0 & $16.00 \%$ & $20.00 \%$ \\
\hline RE & 3 & 60.2 & 28.6 & 0.0 & 50.0 & 50.0 & 75.0 & 100.0 & $4.00 \%$ & $22.00 \%$ \\
\hline $\mathrm{MH}$ & 5 & 52.4 & 21.8 & 0.0 & 45.0 & 50.0 & 60.0 & 100.0 & $2.00 \%$ & $4.00 \%$ \\
\hline PCS & & 46.4 & 10.3 & 27.9 & 37.4 & 46.1 & 56.8 & 62.0 & $2.00 \%$ & $2.00 \%$ \\
\hline MCS & & 38.7 & 10.9 & 15.4 & 32.3 & 38.4 & 43.9 & 62.8 & $2.00 \%$ & $2.00 \%$ \\
\hline
\end{tabular}

\section{Test of scaling assumption for the WHOQOL-BREF vs SF-36 comparison}

To evaluate item internal consistency test and item discriminant validity test for both instruments, multi-trait scaling techniques were used (Table 3). Item internal consistency describes to what extent items belonging to the same scale do correlate one with each other and item discriminant validity shows that items belonging to different scales should not correlate to a great extent.

The range of the item internal consistency for the WHOQOL-BREF was 0.4-0.84 and 0.49-0.97 for Sf-36. A perfect success rate, with the criteria of correlations, which equal or exceed 0.40 , was observed in the tests of the item internal consistency for both instruments. Results of item discriminant validity and scaling success rates are also shown, with a near perfect success rate achieved in tests of the item discriminant validity for both instruments. 
Table 3

Tests of item internal consistency and discriminant validity of the WHOQOL-BREF and SF-36

\begin{tabular}{|c|c|c|c|c|c|c|}
\hline & \multicolumn{2}{|l|}{ Range of Correlations } & \multicolumn{2}{|c|}{ Internal Consistency Tests $\llbracket$} & \multicolumn{2}{|c|}{ 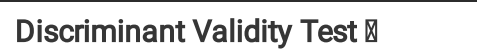 } \\
\hline & Item-internal consistency & $\begin{array}{l}\text { Item-discriminant validity } \\
{[}\end{array}$ & \#Success/total & Success rate (\%) & \#Success/total & Success rate (\%) \\
\hline \multicolumn{7}{|c|}{ WHOQOL-BREF $(n=50)$} \\
\hline Phy & $0.4-0.84$ & $0.01-0.78$ & $7 / 7$ & $100 \%$ & $27 / 28$ & $96 \%$ \\
\hline Psy & $0.53-0.80$ & $0.06-0.78$ & $6 / 6$ & $100 \%$ & $24 / 24$ & $100 \%$ \\
\hline Soc & $0.70-0.81$ & $0.27-0.53$ & $3 / 3$ & $100 \%$ & $12 / 12$ & $100 \%$ \\
\hline Env & $0.46-0.71$ & $0.27-0.74$ & $8 / 8$ & $100 \%$ & $30 / 32$ & $100 \%$ \\
\hline \multicolumn{7}{|c|}{ SF-36 $(n=100)$} \\
\hline PF & $0.64-0.97$ & $0.25-0.78$ & $10 / 10$ & $100 \%$ & $78 / 80$ & $97.5 \%$ \\
\hline $\mathrm{RP}$ & $0.82-0.94$ & $0.31-0.89$ & $4 / 4$ & $100 \%$ & $32 / 32$ & $100 \%$ \\
\hline $\mathrm{BP}$ & $0.79-0.79$ & $0.45-0.74$ & $2 / 2$ & $100 \%$ & $16 / 16$ & $100 \%$ \\
\hline $\mathrm{GH}$ & $0.65-0.80$ & $0.27-0.59$ & $5 / 5$ & $100 \%$ & $39 / 40$ & $97.5 \%$ \\
\hline VT & $0.49-0.73$ & $0.14-0.66$ & $4 / 4$ & $100 \%$ & $32 / 32$ & $100 \%$ \\
\hline SF & $0.88-0.88$ & $0.29-0.63$ & $2 / 2$ & $100 \%$ & $16 / 16$ & $100 \%$ \\
\hline $\mathrm{RE}$ & $0.93-0.97$ & $0.45-0.85$ & $3 / 3$ & $100 \%$ & $24 / 24$ & $100 \%$ \\
\hline $\mathrm{MH}$ & $0.61-0.8$ & $0.27-0.61$ & $5 / 5$ & $100 \%$ & $40 / 40$ & $100 \%$ \\
\hline \multicolumn{7}{|c|}{ \Correlation between items and hypothesized scale corrected for overlap } \\
\hline \multicolumn{7}{|c|}{ ¿Correlation between items and other scales } \\
\hline \multicolumn{7}{|c|}{ هNumber $\geq 0.40$} \\
\hline$\nabla \mathrm{Nur}$ & r of correlations signific & higher/total number of cc & tions & & & \\
\hline
\end{tabular}

\section{Reliability}

Table 4 shows internal consistency for reliability tested by Cronbach's a. The Cronbach's a values for internal consistency (reliability) for all the SF-36 scales were above 0.70 showing good internal reliability of SF-36. The physical, psychological and environmental domains of WHOQOLBREF also had Cronbach's a values above 0.70. The social domain had a lower Cronbach's a than expected at 0.652 . Looking back into the three questions being assessed, it was noted that question 21 dealt with sexual function asking: "How satisfied are you with your sex life?" In the Ethiopian context, discussing your sex life is still fairly taboo and it was theorized that this item was negatively influencing the internal reliability of the social domain. Re-running the analysis by omitting question 21, greatly improved the Cronbach's a from 0.652 to 0.851 (Table 5 ). 
Table 4

Reliability statistics for WHOQOL-BREF and SF-36

\begin{tabular}{|llll|}
\hline QoL questionnaire & Domains & Cronbach's a & N of Items \\
\hline WHOQOL-BREF & Phy & .768 & 7 \\
\cline { 2 - 4 } & Psy & .738 & 6 \\
\hline Soc & .652 & 3 \\
\hline SF-36 & Envir & .744 & 8 \\
\hline PF & .968 & 10 \\
\hline RP & .966 & 4 \\
\hline BP & .923 & 2 \\
\hline GH & .877 & 5 \\
VT & .817 & 4 \\
\hline SF & .928 & 2 \\
\hline RE & .975 & 3 \\
\hline MH & .894 & 4 \\
\hline
\end{tabular}

Table 5

Reliability Statistics for WHOQOL social domain

\begin{tabular}{|c|c|c|c|}
\hline & Cronbach's a & Cronbach's a Based on Standardized Items & N of Items \\
\hline Qu 20,21 and 22 & .652 & .685 & 3 \\
\hline Qu 20 and 22 only & .851 & .854 & 2 \\
\hline
\end{tabular}

\section{Convergent and discriminant validity}

The correlations for inter-domain/scale of the WHOQOL-BREF and the SF-36 are presented in Table 6 . The range of correlations for interdomain/scales of the WHOQOL-BREF is $0.46-0.76$ (all p<0.001), showing a range of moderate (30\%) to high (60\%) associations among domains. All the inter-scale correlations of the SF-36 showed moderate (14\%) to high $(76 \%)$ associations $(r$ range $0.38-0.89$, all $p<0.001)$. Within WHOQOLBREF, the range of correlation between the general QoL question (Q1) and the domains was from 0.21-0.69, whilst between the general health question $(\mathrm{GH} 1)$ and the domains it was 0.25- 0.43). The correlations were between the social domain and general QoL and health questions ( $r=0.21$ and $r=0.27$ respectively) and the environmental domain and the general health question $(r=0.25)$. Within SF-36, there was good correlation between the general health question $(\mathrm{GH})$ and all the scale ( $r$ range 0.47-0.76). 
Pearson's Correlation Coefficients between WHOQOL-BREF and SF-36 $(n=50)$

\begin{tabular}{|c|c|c|c|c|c|c|c|c|c|c|c|c|c|c|}
\hline & WHOQ & L-BREF & & & & & SF-36 & & & & & & & \\
\hline Name & Q1 & $\mathrm{GH} 1$ & PHY & PSY & SOC & ENV & PF & RP & BP & $\mathrm{GH}$ & VT & SF & RE & $\mathrm{MH}$ \\
\hline Q1 & 1.00 & & & & & & & & & & & & & \\
\hline GH1 & $0.41^{\star \star}$ & 1.00 & & & & & & & & & & & & \\
\hline PHY & $0.69^{\star \star}$ & $0.43^{\star \star}$ & 1.00 & & & & & & & & & & & \\
\hline PSY & $0.56^{\star \star}$ & $0.32^{*}$ & $0.76^{* *}$ & 1.00 & & & & & & & & & & \\
\hline soc & 0.21 & 0.27 & $0.46^{* *}$ & $0.48^{\star *}$ & 1.00 & & & & & & & & & \\
\hline ENV & $0.48^{\star \star}$ & 0.25 & $0.64^{\star *}$ & $0.68^{\star *}$ & $0.50^{\star *}$ & 1.00 & & & & & & & & \\
\hline PF & 0.23 & $0.46^{\star *}$ & $0.33^{*}$ & $0.32^{\star}$ & 0.25 & 0.20 & 1.00 & & & & & & & \\
\hline RP & $0.34^{*}$ & $0.59^{\star \star}$ & $0.46^{* *}$ & $0.35^{\star}$ & 0.17 & $0.30^{*}$ & $0.58^{\star *}$ & 1.00 & & & & & & \\
\hline $\mathrm{BP}$ & $0.36^{*}$ & $0.76^{\star \star}$ & $0.47^{* *}$ & $0.35^{\star}$ & 0.16 & 0.21 & $0.54^{\star *}$ & $0.70^{\star *}$ & 1.00 & & & & & \\
\hline GH & 0.25 & $0.78^{\star \star}$ & 0.28 & 0.26 & 0.10 & 0.19 & $0.41^{\star *}$ & $0.60^{\star *}$ & $0.75^{* *}$ & 1.00 & & & & \\
\hline VT & $0.33^{*}$ & $0.70^{\star \star}$ & $0.42^{\star *}$ & $0.39^{\star \star}$ & 0.05 & 0.23 & $0.38^{\star *}$ & $0.55^{\star \star}$ & $0.66^{\star *}$ & $0.70^{\star *}$ & 1.00 & & & \\
\hline SF & 0.16 & $0.68^{\star \star}$ & $0.38^{* *}$ & 0.25 & 0.15 & $0.37^{*}$ & $0.39^{\star *}$ & $0.57^{\star *}$ & $0.72^{* *}$ & $0.59^{\star *}$ & $0.55^{\star *}$ & 1.00 & & \\
\hline RE & $0.44^{\star \star}$ & $0.52^{\star \star}$ & $0.62^{* *}$ & $0.50^{\star \star}$ & 0.19 & $0.30^{*}$ & $0.64^{*}$ & $0.74^{\star *}$ & $0.71^{* *}$ & $0.50^{\star *}$ & $0.54^{\star \star}$ & $0.57^{\star \star}$ & 1.00 & \\
\hline MH & $0.51^{\star \star}$ & $0.67^{\star \star}$ & $0.60^{\star *}$ & $0.46^{\star \star}$ & 0.08 & $0.34^{*}$ & $0.46^{\text {** }}$ & $0.47^{\star \star}$ & $0.73^{\text {** }}$ & $0.62^{\star \star}$ & $0.63^{\star \star}$ & $0.60^{\star *}$ & $0.65^{\star *}$ & 1.00 \\
\hline PCS & 0.23 & $0.67^{\star \star}$ & $0.32^{*}$ & $0.29^{\star}$ & 0.22 & 0.20 & $0.81^{\star *}$ & $0.83^{\star *}$ & $0.80^{\star *}$ & $0.76^{\star \star}$ & $0.59^{\star \star}$ & $0.59^{\star *}$ & $0.65^{\star *}$ & $0.49^{\star \star}$ \\
\hline MCS & $0.45^{\star \star}$ & $0.70^{\star *}$ & $0.61^{* *}$ & $0.47^{\star *}$ & 0.06 & $0.35^{\star}$ & $0.35^{\star}$ & $0.54^{\star *}$ & $0.75^{\star \star}$ & $0.63^{\star \star}$ & $0.75^{\star \star}$ & $0.77^{\star *}$ & $0.77^{\star *}$ & $0.89^{\star *}$ \\
\hline
\end{tabular}

**. Correlation is significant at the 0.001 level (2-tailed).

*. Correlation is significant at the 0.05 level (2-tailed).

Q1-overall QOL in WHOQOL-BREF, GH1-general health in WHOQOL-BREF, Phy-physical domain, Psy-psychological domain, Soc-social domain, Env-environment domain, PF-physical functioning, RP-role physical, BP-bodily pain, GH-general health perceptions, VT-vitality, SF-social functioning, RE-role emotional, MH-mental health, PCS-physical component summary, MCS-mental component summary

In analysing level of correlation, the following have been assumed: High correlation: 0.5 to 1.0 or -0.5 to 1.0;

Moderate correlation: 0.3 to 0.5 or -0.3 to 0.5 ; Low correlation: 0.1 to 0.3 or -0.1 to -0.3

Correlation between scores of the WHOQOL-BREF and the SF-36 are also shown in this table. The relationship of the general item, Q1 (overall QoL from WHOQOL-BREF) showed weak to moderate associations with scales of SF-36, including with the general health question $\mathrm{GH}$ ( $r=0.41$, $\mathrm{p}<0.001)$. The highest association ( $r=0.51$ ) was between Q1 and $\mathrm{MH}$ of the SF-36. This implies that both measured similar concepts. Question GH from SF-36 showed weak to moderate associations with WHOQOL-BREF domains but a high association ( $r=0.78)$ with GH1 implying that both measured similar concepts, and that participants were responding to this question consistently with both questionnaires. The hypothesis that domain/scale scores should be positively correlated to self-perceived health status is better supported with the SF-36 in this group of patients.

Looking in more detail at the associations between the SF-36 scales and the WHOQOL-BREF domains, weak associations occurred between the social domain of WHOQOL-BREF and all SF-36 scale items ( $r$ range $0.05-0.25$ ), as well as between the environmental domain of WHOQOL-BREF and scale items PF, BP, GH, and VT of the SF-36 ( $r$ range 0.19-0.23). Moderate associations were seen between the physical domain of WHOQOLBREF and PF, RP, BP, GH and VT of SF-36 ( $r$ range 0.28 and 0.47); and the psychological domain of WHOQOL-BREF and PF, BP, RP, VT and MH of SF-36 ( $r$ range 0.32-0.46). The highest correlations were found between the physical domains of WHOQOL-BREF and RE ( $r=0.62)$ and MH ( $r=0.60)$ of the SF-36. 
The correlation between the physical and psychological domains of the WHOQOL-BREF and PF and MH of the SF-36 were 0.33 and 0.46 respectively, but the association between the social domain and SF scale was low $(r=0.15)$. The first hypothesis that the corresponding domain/scale of both instruments should be positively correlated is partially supported.

Regarding the summary measures of the SF-36, the physical domain of the WHOQOL-BREF has weak association with PCS ( $r=0.32$ ) and the psychological domain of WHOQOL-BREF has strong association with MCS ( $r=0.47)$. A weak association was found between the psychological domains of the WHOQOL-BREF and PCS of SF-36 ( $r=0.29)$. This supports the hypothesis that the psychological domain of WHOQOL-BREF should have weak association with PCS, but the correlation between the physical domain and MCS was found to be strong ( $r=0.61$ ).

Within SF-36, the strongest association were between PCS and PF, RP, BP and GH (0.75-0.83) and between MCS and BP, VT, SF, RE and MH (0.760.89). Previous studies have found that, three scales (PF, RP, BP) correlated most highly with the physical component (PCS) measure whilst the mental component (MCS) correlated most highly with the MH, RE, and SF scales $(19,28,29)$.

Overall, the results of validity examination showed that SF-36 has better convergent and discriminant validity than WHOQOL-BREF in this group of participants. The social domain of WHOQOL-BREF showed particularly poor correlation, which might be related to the small number of questions in this domain or to poor internal validity of this domain (Cronbach's $a=0.652$ ).

\section{Known group validity}

Table 7 shows that, in general, leprosy affected individuals with a greater number of symptoms scored significantly lower on the physical domain of WHOQOL-BREF and in three scales of SF-36 (RP, BP, MH) and MCS (all p<0.05). Patients with less severe symptoms scored significantly higher scores on physical, psychological and environmental domains as well almost all the scales of SF-36. This supports the fourth hypothesis and indicated good known-groups validity of both instruments.

Table 7

Comparison of the mean scores in different domains of WHOQOL-BREF and SF-36 for leprosy affected individuals with different symptoms severity

\begin{tabular}{|c|c|c|c|c|c|c|c|c|c|c|c|c|c|c|c|}
\hline & & \multicolumn{4}{|c|}{ WHOQOL-BREF } & \multicolumn{10}{|c|}{ SF-36 } \\
\hline & & PHYS & PSYCH & $\begin{array}{l}\text { SOC- } \\
\text { IAL }\end{array}$ & ENVIR & PF & RP & BP & GH & VT & SF & RE & $\mathrm{MH}$ & PCS & MCS \\
\hline \multirow{3}{*}{$\begin{array}{l}\text { Severity } \\
\text { Level }\end{array}$} & None & 67.9 & 68.8 & 41.7 & 52.3 & 76.3 & 87.5 & 83.0 & 69.3 & 73.4 & 62.5 & 87.5 & 80.0 & 51.7 & 51.4 \\
\hline & Low & 55.5 & 56.6 & 54.3 & 44.9 & 75.7 & 69.6 & 61.5 & 56.8 & 57.1 & 60.3 & 63.0 & 55.2 & 49.7 & 40.3 \\
\hline & High & 43.7 & 48.0 & 38.3 & 34.6 & 66.5 & 48.9 & 34.7 & 39.9 & 49.7 & 33.2 & 52.5 & 44.8 & 42.2 & 34.9 \\
\hline $\mathrm{p}$ value & & $\begin{array}{l}< \\
0.001\end{array}$ & $<0.001$ & & $\begin{array}{l}< \\
0.001\end{array}$ & & $\begin{array}{l}< \\
0.001\end{array}$ & $\begin{array}{l}< \\
0.001\end{array}$ & $\begin{array}{l}< \\
0.001\end{array}$ & & $\begin{array}{l}< \\
0.05\end{array}$ & $<.05$ & $\begin{array}{l}<.05 \\
0.05\end{array}$ & $\begin{array}{l}<.05 \\
0.05\end{array}$ & $<.05$ \\
\hline \multirow{3}{*}{$\begin{array}{l}\text { Number of } \\
\text { symptoms }\end{array}$} & None & 67.9 & 68.8 & 41.7 & 52.3 & 76.3 & 87.5 & 83.0 & 69.3 & 73.4 & 62.5 & 87.5 & 80.0 & 51.7 & 51.4 \\
\hline & $1-3$ & 56.4 & 52.9 & 42.5 & 40.9 & 83.0 & 75.6 & 57.7 & 59.4 & 63.8 & 63.8 & 68.3 & 64.0 & 50.1 & 43.9 \\
\hline & $4-7$ & 47.8 & 52.2 & 47.6 & 39.5 & 67.8 & 54.7 & 45.4 & 45.3 & 50.5 & 42.0 & 54.9 & 46.1 & 44.8 & 35.9 \\
\hline $\mathrm{p}$ value & & $\begin{array}{l}< \\
0.05\end{array}$ & & & & & $\begin{array}{l}< \\
0.001\end{array}$ & $\begin{array}{l}< \\
0.05\end{array}$ & & & & & $<.001$ & & $<.001$ \\
\hline
\end{tabular}

\section{Inter-rater reliability}

One way of performing reliability testing is to use the intra-class correlation coefficient (ICC). It can be defined as, "the proportion of variance of an observation due to between-subject variability in the true scores". The range of the ICC may be between 0.0 and 1.0 . The ICC will be high when there is little variation between the scores given to each item by the raters, e.g. if all raters give the same, or similar scores to each of the items. The ICC is an improvement over Pearson's and Spearman's, as it takes into account of the differences in ratings for individual segments, along with the correlation between raters (30).

In this study intra-class correlation was calculated by using ICC (2), "Two-Way Random" method which works on two assumptions: 1) it models both an effect of rater and of ratee (i.e. two effects) and 2) assumes both are drawn randomly from larger populations (i.e. a random effects model). Mean rating was selected, computing first the mean of each of the 8 domains of SF-36 (PF, RP, BP, GH, VT, SF, RE, MH), for each of the 50 participants in both sets of interviews. The measure of consistency was chosen as this is recommended when comparing means and results are summarized in Table 8. 
Table 8

Intra-class Correlation Coefficient

\begin{tabular}{|c|c|c|c|c|c|c|c|}
\hline \multirow[t]{2}{*}{ SF-36 domain } & \multirow[t]{2}{*}{ Intra-class Correlation囚 Average Measures } & \multicolumn{2}{|c|}{ 95\% Confidence Interval } & \multicolumn{4}{|c|}{ F Test with True Value 0} \\
\hline & & Lower Bound & Upper Bound & Value & df1 & df2 & Significance \\
\hline PF & .830 & .700 & .903 & 5.873 & 49 & 49 & .000 \\
\hline RP & .737 & .537 & .851 & 3.804 & 49 & 49 & .000 \\
\hline BP & .809 & .664 & .892 & 5.239 & 49 & 49 & .000 \\
\hline GH & .987 & .977 & .993 & 76.179 & 49 & 49 & 0.000 \\
\hline VT & .988 & .978 & .993 & 81.584 & 49 & 49 & 0.000 \\
\hline SF & .976 & .957 & .986 & 41.101 & 49 & 49 & 0.000 \\
\hline RE & .805 & .657 & .890 & 5.140 & 49 & 49 & .000 \\
\hline $\mathrm{MH}$ & .934 & .884 & .963 & 15.178 & 49 & 49 & 0.000 \\
\hline
\end{tabular}

An intra-class correlation of 0.7 is deemed acceptable, above 0.8 is optimal and a score of above 0.9 would be considered excellent inter-rater reliability. Our results show that for four out of the eight domains of SF-36 inter-rater reliability was excellent, three were in the optimal range and one, social functioning was in the acceptable range. The $\mathrm{p}$-values, all under 0.001 , were statistically significant.

\section{Discussion}

This study assessed the reliability and validity of our Amharic version of the SF-36 by comparing it to the Amharic WHOQOL-BREF in measuring HRQoL in individuals with leprosy.

The Amharic translation of SF-36 was translated following standard procedures(31). Interviewers reported that it was easy to use and that most participants understood the questions.

Descriptive statistics revealed positively skewed score distributions of the WHOQOL-BREF domains and SF-36 scales indicating more patients scored less than the mean group scores. Taking into consideration that $69 \%$ of patients interviewed were attending hospital because they were unwell, this result would be expected, and would be an indication of validity. This was further supported by the high ceiling effect noted in the PF scale of SF-36 (34\%) and 24\% for RP and 25\% for RE, supporting the theory that our patient group would have a large proportion that would have some limitations in physical functioning, and work/social activities.

Comparison between the Amharic SF-36 and the validated Amharic WHOQOL-BREF found that item internal consistency and item discriminant validity were good. Internal consistency reliability estimates for each domain/scale exceeded 0.70, except for the social domain of WHOQOLBREF where results were heavily skewed by Question 21 relating to satisfaction in sex life. This is traditionally a taboo subject in Ethiopia, and a subject that is often difficult to discuss with healthcare professionals. The strong correlation between all, except the social, WHOQOL-BREF domains with the mental component rather than the physical component may reflect the strong mental health component of the WHOQOL-BREF. The Amharic SF-36 may have better reliability than the Amharic WHOQOL-BREF in this group of participants.

The results of validity examination showed that convergent and discriminant validity for SF-36 inter-Scale was better than that for WHOQOL-BREF inter-domain, in this group of participants. Correlations between the scores of corresponding domains/scales between the WHOQOL-BREF and SF-36 supported the first hypothesis that the corresponding domain/scale of both instruments should be positively correlated with the exception that the association between the social domain and SF scale was low ( $r=0.15)$. The second hypothesis stating that the physical and psychological domains of the WHOQOL-BREF should have weak associations with MCS and PCS of the SF-36, respectively was partially supported as the correlation between the physical domain and MCS was found to be strong $(r=0.61)$, possibly reflecting the strong mental health component of the WHOQOL-BREF. The third hypothesis that domain/scale scores should be positively correlated to self-perceived health status is better supported with the SF-36 in this group of patients. Good known-group validity for both instruments supported the fourth hypothesis as there was a consistent trend of decreasing scores in the WHOQOL-BREF and SF-36 with increasing severity and number of leprosy related symptoms. 
The inter-rater reliability was very good with all the scales scoring between the acceptable and excellent range (32).

At the commencement of our study, there were two published studies assessing quality of life using SF-36 in leprosy in a clinical situation. Both studies were based in Brazil. One assessed the quality of life in 107 patients attending a health facility for leprosy treatment (13) and the second quality of life in 49 patients on treatment for paucibacillary (PB) leprosy (14). The second study found that quality of life scores in $63 \%$ of patients with PB leprosy was not affected. Most of these patients were diagnosed early with no leprosy reaction or nerve function impairment. The study of Lustosa et al. (13) found that patients with reactions, increased disability grades and a perception of stigma had a significantly lower score in all scales of SF-36. Recently, more studies with people affected by leprosy are reporting the use of SF-36 to assess HRQoL. In Bangladesh, 29 patients with erythema nodosum leprosum (ENL), a chronic and often severe complication of leprosy, had significantly worse HRQoL in all 8 domains of SF-36, compared to 46 leprosy patients without ENL (33). Similar findings in Brazil, discussed the effect of ENL on the HRQoL of leprosy patients as measured by SF-36 (34). In 2019, a Brazilian study compared SF-36 and DLQI in leprosy patients, finding that SF-36 was the better HRQoL assessment tool covering non- dermatological sequelae of leprosy such as body or nerve pain, and disability (35). The use of SF-36 is reported in African leprosy patients for the first time here.

The Amharic SF-36 scores in our sample of 100 Ethiopians with leprosy were much lower compared to the Ethiopian normative data (20). The difference was more marked in the scales regarding bodily pain and social functioning. This may be explained by the fact that $81 \%$ of patients interviewed were on treatment for leprosy reaction, $31 \%$ were acutely unwell on the day of the interview and $46 \%$ had severe symptoms. The significant relationship between reduced HRQoL and physical pain has been previously described in other studies (10). The lower social scores in the social functioning of individuals with leprosy may be a reflection of the stigma that exists in leprosy. The scores in both emotional and physical role scales were lower in leprosy affected people indicating difficulties with work or other activities as a result of physical health and emotional problems.

In our study, strong correlations were found between higher grades of disability (determined by EHF scores) and lower SF-36 scores, in particular in PF, BP, SF, RE, MH, PCS, and MCS. The correlation between higher level of severity of symptoms and lower HRQoL scores was statistically significant in all the scales of SF-36. This was also mostly true for the number of symptoms experienced and for patients who were unwell on the day of the interview. These differences in scores in the Amharic SF-36 between patient categories indicate that the questionnaire has good construct validity.

The study is not without limitations. Self-administered questionnaires are preferable. Using interviewers is essential in populations were literacy rates and levels of education are low, but conversations and explanations may have influenced some of the answers.

\section{Conclusion}

Our Amharic version of the SF-36 is valid and reliable. We are confident that this instrument is useful to measure HRQoL in clinical trials involving Ethiopian participants with leprosy.

\section{List Of Abbreviations}




\begin{tabular}{|c|c|}
\hline AHRI & Armauer Hansen Research Institute \\
\hline ALERT & All Africa Leprosy Rehabilitation and Training Center \\
\hline $\mathrm{BP}$ & bodily pain \\
\hline DLQI & Dermatology Life Quality Index \\
\hline EHF & Eye, hand and foot score \\
\hline ENL & Erythema nodosum leprosum \\
\hline Env & environment domain \\
\hline $\mathrm{GH}$ & general health perceptions \\
\hline HRQoL & Health-related quality of life \\
\hline MDT & Multi-drug therapy \\
\hline $\mathrm{MH}$ & mental health \\
\hline PCS & physical component summary \\
\hline PF & physical functioning \\
\hline Phy & physical domain \\
\hline Psy & psychological domain \\
\hline $\mathrm{RE}$ & role emotional \\
\hline $\mathrm{RP}$ & role physical \\
\hline SF & social functioning \\
\hline SF-36 & 36-Item Short Form Health Survey \\
\hline Soc & social domain \\
\hline T1R & Type 1 Reaction \\
\hline VT & vitality \\
\hline WHO & World Health Organisation \\
\hline WHOQOL-BREF & World Health Organisation Quality of Life Bref \\
\hline
\end{tabular}

\section{Declarations}

\section{Ethics approval and consent to participate}

Ethical approval was obtained as part of the larger clinical trial from Ethics Committee of the London School of Hygiene and Tropical Medicine (5376), the ALERT and AHRI Ethical Review Committee (AA/ht/248/09), the National Ethics Review Committee of Ethiopia (RDHE/34-90/2009). Written informed consent was obtained in Amharic. Data was anonymised and stored in a password protected Access database.

Non-commercial licence agreement with Quality metric: QM011524

\section{Consent for publication}

Not applicable.

Availability of data and materials

The datasets used and/or analysed during the current study are available from the corresponding author on reasonable request.

\section{Competing interests}

The authors declare that they have no competing interests.

\section{Funding}

This study was supported by a grant by the Hospital and Homes of St Giles, as part of the Ciclosporin in Leprosy Reactions clinical trials (36,37). 
SML, PGN conceived the study. SML and SDN supervised the study. SML conducted the analysis. SML, SDN, PGN and DNJL interpreted the findings. All authors read and approved the final manuscript.

Acknowledgments

We are grateful to all the participants of this study for their valuable participation.

\section{References}

1. Lockwood DNJ. Leprosy. In: Burns DA, Breathnach SM, Cox NH, Griffiths CEM, editors. Rook's textbook of Dermatology, 7th ed. 7th ed. Blackwell Publishing, Oxford; 2004. p. 1215-35.

2. World Health Organization. WHO Weekly Epidemiological Review [Internet]. WER 9536. 2020 [cited 2021 Jun 25]. Available from: https://reliefweb.int/sites/reliefweb.int/files/resources/WER9536-eng-fre.pdf

3. Chandler DJ, Hansen KS, Mahato B, Darlong J, John A, Lockwood DNJ. Household costs of leprosy reactions (ENL) in rural India. PLoS Negl Trop Dis [Internet]. 2015 Jan 15 [cited 2015 Sep 17];9(1):e0003431. Available from: http://journals.plos.org/plosntds/article? id=10.1371/journal.pntd.0003431

4. Seddon D, Seeley J. Leprosy and stigma. Asia Pacific Disabil Rehabil J [Internet]. 2006 [cited 2015 Sep 18];Vol. 17(No. 2):3-6. Available from: http://english.aifo.it/disability/apdrj/apdrj206/guested-leprosy.pdf

5. Walker SL, Lebas E, Doni SN, Lockwood DNJ, Lambert SM. The mortality associated with erythema nodosum leprosum in ethiopia: a retrospective hospital-based study. PLoS Negl Trop Dis [Internet]. 2014 Mar [cited 2014 May 27];8(3):e2690. Available from: http://www.pubmedcentral.nih.gov/articlerender.fcgi?artid=3953021\&tool=pmcentrez\&rendertype=abstract

6. Mieras L et al. Global Partnership on Zero Leprosy Research Agenda Working Group Subgroup on Disability [Internet]. Global Partnership on Zero Leprosy (GPZL). 2019 [cited 2021 Jun 25]. Available from: https://zeroleprosy.org/wp-content/uploads/2019/06/GPZL-RWGDisability.pdf

7. Joseph GA, Rao PS. Impact of leprosy on the quality of life. Bull World Health Organ [Internet]. 1999 Jan [cited 2013 Sep 1];77(6):515-7. Available from: http://www.pubmedcentral.nih.gov/articlerender.fcgi?artid=2557686\&tool=pmcentrez\&rendertype=abstract

8. Tsutsumi A, Izutsu T, Islam AM, Maksuda AN, Kato H, Wakai S. The quality of life, mental health, and perceived stigma of leprosy patients in Bangladesh. Soc Sci Med [Internet]. 2007/03/27. 2007;64(12):2443-53. Available from: http://www.ncbi.nlm.nih.gov/entrez/query.fcgi? cmd=Retrieve\&db=PubMed\&dopt=Citation\&list_uids=17382441

9. Mankar MJ, Joshi SM, Velankar DH, Mhatre RK, Nalgundwar AN. A Comparative Study of the Quality of Life, Knowledge, Attitude and Belief About Leprosy Disease Among Leprosy Patients and Community Members in Shantivan Leprosy Rehabilitation centre, Nere, Maharashtra, India. J Glob Infect Dis [Internet]. 2011 Oct [cited 2014 May 5];3(4):378-82. Available from: http://www.pubmedcentral.nih.gov/articlerender.fcgi?artid=3249995\&tool=pmcentrez\&rendertype=abstract

10. Costa MD, Terra F de S, Costa RD, Lyon S, Costa AMDD, Antunes CM de F. Assessment of quality of life of patients with leprosy reactional states treated in a dermatology reference center. An Bras Dermatol [Internet]. 2012 [cited 2013 Aug 25];87(1):26-35. Available from: http://www.ncbi.nlm.nih.gov/pubmed/22481648

11. An J-G, Ma J-H, Xiao S-X, Xiao S-B, Yang F. Quality of life in patients with lepromatous leprosy in China. J Eur Acad Dermatology Venereol [Internet]. 2010 Jul [cited 2013 Aug 11];24(7):827-32. Available from: http://www.ncbi.nlm.nih.gov/pubmed/20015055

12. Proto RS, Machado Filho CDS, Rehder JRCL, Paixão MP, Angelucci RI. Quality of life in leprosy: a comparative analysis between patients in the Amazon region and patients in Santo André in the ABC region of São Paulo, Brazil. An Bras Dermatol [Internet]. 2010 [cited 2013 Aug 26];85(6):939-41. Available from: http://www.ncbi.nlm.nih.gov/pubmed/21308328

13. Lustosa AA, Nogueira LT, Pedrosa JIDS, Teles JBM, Campelo V. The impact of leprosy on health-related quality of life. Rev Soc Bras Med Trop [Internet]. 2011 Oct [cited 2013 Sep 2];44(5):621-6. Available from: http://www.scielo.br/scielo.php?script=sci_arttext\&pid=S0037$86822011000500019 \&$ Ing=en\&nrm=iso\&tlng=en

14. Bottene IMC, Reis VMS dos. Quality of life of patients with paucibacillary leprosy. An Bras Dermatol [Internet]. 2012 [cited 2014 May 5];87(3):408-11. Available from: http://www.ncbi.nlm.nih.gov/pubmed/22714756

15. WHO. World Health Orgaization. Division Of Mental Health And Prevention Of Substance Abuse: WHOQOL User Manual. Geneva, Switzerland; 2012.

16. Araya M, Chotai J, Komproe IH, de Jong JTVM. Quality of life after postconflict displacement in Ethiopia: comparing placement in a community setting with that in shelters. Soc Psychiatry Psychiatr Epidemiol [Internet]. 2011 Jul [cited 2013 Aug 23];46(7):585-93. Available from: http://www.ncbi.nlm.nih.gov/pubmed/20383488 
17. Mousley E, Deribe K, Tamiru A, Davey G. The impact of podoconiosis on quality of life in Northern Ethiopia. Health Qual Life Outcomes [Internet]. 2013 Jan [cited 2013 Aug 26];11:122-34. Available from: http://www.pubmedcentral.nih.gov/articlerender.fcgi? artid=3726315\&tool=pmcentrez\&rendertype=abstract

18. Henok L, Davey G. Validation of the Dermatology Life Quality Index among patients with podoconiosis in southern Ethiopia. Br J Dermatol [Internet]. 2008 Sep [cited 2013 Sep 1];159(4):903-6. Available from: http://www.ncbi.nlm.nih.gov/pubmed/18671781

19. Ware JE. SF-36 Health Survey: Manual and Interpretation Guide. Boston, Massachusetts: The Health Institute, New England Medical Center.; 1993. $1993 \mathrm{p}$.

20. Kebede D, Alem A, Shibre T, Negash A, Deyassa N, Beyero T. Health related quality of life (SF-36) survey in Butajira, rural Ethiopia: normative data and evaluation of reliability and validity. Ethiop Med J [Internet]. 2004;42(4):289-97. Available from:

http://www.ncbi.nlm.nih.gov/pubmed/16122121

21. Kebede D, Alem A, Shibre T, Negash A, Deyassa N, Beyero T, et al. Short-term symptomatic and functional outcomes of schizophrenia in Butajira, Ethiopia. Schizophr Res [Internet]. 2005 Oct 15 [cited 2014 May 7];78(2-3):171-85. Available from: http://www.ncbi.nlm.nih.gov/pubmed/16112845

22. Kebede D, Alem A, Shibire T, Deyassa N, Negash A, Beyero T, et al. Symptomatic and functional outcome of bipolar disorder in Butajira, Ethiopia. J Affect Disord. 2006;90(2-3):239-49.

23. Abera K, Gedif T, Engidawork E, Gebre-Mariam T. Quality of life of people living with HIV/AIDS and on highly active antiretroviral therapy in Ethiopia. African J AIDS Res [Internet]. 2010 Apr 1 [cited 2013 Aug 25];9(1):31-40. Available from: http://www.informaworld.com/openurl? genre=article \&doi=10.2989/16085906.2010.484560\&magic=crossref\%7C\%7CD404A21C5BB053405B1A640AFFD44AE3

24. Gandek B, Ware JE, Aaronson NK, Apolone G, Bjorner JB, Brazier JE, et al. Cross-validation of item selection and scoring for the SF-12 Health Survey in nine countries: results from the IQOLA Project. International Quality of Life Assessment. J Clin Epidemiol [Internet]. 1998 Nov [cited 2013 Aug 26];51(11):1171-8. Available from: http://www.ncbi.nlm.nih.gov/pubmed/9817135

25. Hsiung P-C, Fang C-T, Chang Y-Y, Chen M-Y, Wang J-D. Comparison of WHOQOL-bREF and SF-36 in patients with HIV infection. Qual Life Res [Internet]. 2005 Feb [cited 2013 Aug 27];14(1):141-50. Available from: http://www.ncbi.nlm.nih.gov/pubmed/15789948

26. Araya M, Chotai J, Komproe IH, de Jong JTVM. Effect of trauma on quality of life as mediated by mental distress and moderated by coping and social support among postconflict displaced Ethiopians. Qual Life Res [Internet]. 2007 Aug [cited 2013 Aug 26];16(6):915-27. Available from: http://www.ncbi.nlm.nih.gov/pubmed/17440829

27. Brandsma JW, Van Brakel WH. WHO disability grading: operational definitions. Lepr Rev [Internet]. 2003 Dec [cited 2013 Sep 1];74(4):366-73. Available from: http://www.ncbi.nlm.nih.gov/pubmed/14750582

28. Gandek B, Ware JE, Aaronson NK, Alonso J, Apolone G, Bjorner J, et al. Tests of data quality, scaling assumptions, and reliability of the SF-36 in eleven countries: results from the IQOLA Project. International Quality of Life Assessment. J Clin Epidemiol [Internet]. 1998 Nov 1 [cited 2014 May 11];51(11):1149-58. Available from: http://www.jclinepi.com/article/S0895-4356(98)00106-1/abstract

29. McHorney CA, Ware JE, Raczek AE. The MOS 36-Item Short-Form Health Survey (SF-36): Il. Psychometric and clinical tests of validity in measuring physical and mental health constructs. Med Care [Internet]. 1993 Mar [cited 2014 Apr 28];31(3):247-63. Available from: http://www.ncbi.nlm.nih.gov/pubmed/8450681

30. Shrout PE, Fleiss JL. Intraclass correlations: uses in assessing rater reliability. Psychol Bull [Internet]. 1979 Mar [cited 2013 Aug 7];86(2):4208. Available from: http://www.ncbi.nlm.nih.gov/pubmed/18839484

31. Acquadro C, Conway K, Hareendran A, Aaronson N. Literature review of methods to translate health-related quality of life questionnaires for use in multinational clinical trials. Value Heal [Internet]. 2008 [cited 2021 Jan 24];11(3):509-21. Available from: https://pubmed.ncbi.nlm.nih.gov/18179659/

32. Landis JR, Koch GG. The Measurement of Observer Agreement for Categorical Data. Biometrics. 1977 Mar;33(1):159.

33. Bowers B, Butlin RC, Alam K, Lockwood DNJ, Walker SL. Health-Related Quality of Life amongst people affected by Erythema Nodosum Leprosum in Bangladesh: a Cross Sectional Study. Lepr Rev [Internet]. 2017 [cited 2019 Sep 26];(88):488-98. Available from: https://www.lepra.org.uk/platforms/lepra/files/Ir/Dec17/Lep488-498.pdf

34. Sales A, Illarramendi X, Walker SL, Lockwood DNJ, Sarno EN, Nery JA (2017). LR 88. 499-509. The impact of Erythema Nodosum Leprosum on health related quality of life in Rio de Janeiro. Lepr Rev [Internet]. 2017 [cited 2019 Sep 26];(88):499-509. Available from:

https://www.lepra.org.uk/platforms/lepra/files/lr/Dec17/Lep499-509.pdf

35. Guimenes Albuquerque R, Grüdtner Buratto G, Hirotsu C, Maeda SM, Floriano MC, Levy Andersen M, et al. Comparison of quality of life evaluated by SF -36 and DLQI in multibacillary and paucibacillary leprosy patients from Sao Paulo, Brazil. Int J Dermatol [Internet]. 2019 May 30 [cited 2019 Sep 26];ijd.14489. Available from: https://onlinelibrary.wiley.com/doi/abs/10.1111/ijd.14489

36. Lambert SM, Alembo DT, Nigusse SD, Yamuah LK, Walker SL, Lockwood DNJ. A Randomized Controlled Double Blind Trial of Ciclosporin versus Prednisolone in the Management of Leprosy Patients with New Type 1 Reaction, in Ethiopia. PLoS Negl Trop Dis [Internet]. 2016 Apr 5 [cited 2021 Jun 25];10(4). Available from: https://pubmed.ncbi.nlm.nih.gov/27046330/

Page 16/17 
37. Lambert SM, Nigusse SD, Alembo DT, Walker SL, Nicholls PG, Idriss MH, et al. Comparison of Efficacy and Safety of Ciclosporin to Prednisolone in the Treatment of Erythema Nodosum Leprosum: Two Randomised, Double Blind, Controlled Pilot Studies in Ethiopia. PLoS Negl Trop Dis [Internet]. 2016 Feb 26 [cited 2021 Jun 25];10(2). Available from: https://pubmed.ncbi.nlm.nih.gov/26919207/

\section{Supplementary Files}

This is a list of supplementary files associated with this preprint. Click to download.

- Appendix1.docx

- AMHARICSF36FinalAug2013SLpub.pdf 